\title{
Severe Combined Immunodeficiency due to NHEJ1 Deficiency
}

National Cancer Institute

\section{Source}

National Cancer Institute. Severe Combined Immunodeficiency due to NHE/1 Deficiency.

NCl Thesaurus. Code C162695.

An autosomal recessive condition caused by mutation(s) in the NHEJ1 gene, encoding non-homologous end-joining factor 1. It is characterized by severe combined immunodeficiency that is T-cell negative, B-cell negative, NK-cell positive. Microcephaly, growth retardation, and sensitivity to ionizing radiation are also characteristic of this disease. 